\title{
Mudança de época e conversão pastoral: Uma leitura das conclusões de Aparecida
}

\author{
Joel Portella Amado
}

\section{Introdução}

Esta Semana Teológica se insere no que podemos chamar de terceiro momento da Conferência de Aparecida, isto é, o período de recepção e aplicação pelas Igrejas do Continente. Após as etapas de preparação e realização, a Conferência se projeta sobre a vida das mesmas Igrejas, solicitando delas o acolhimento e a colocação em prática com destaques e opções na ação evangelizadora. Torna-se motivação, por exemplo, para diretrizes e planejamentos pastorais, suscita reflexão do mundo acadêmico e estimula a vida espiritual. Suas conclusões são vinculantes, no sentido de que não se pode voltar atrás no que ali foi indicado. Por isso, importa, neste momento de contato inicial com as Conclusões, ter o cuidado em relação a leituras muito pontuais e apego a trechos muito específicos. A fidelidade às Conclusões pede uma leitura inicial mais ampla, que percorra todo o documento, buscando suas intuições gerais, para, só então, mergulhar nos aspectos particulares.

Longe de balizar totalmente a etapa de recepção da V Conferência, esta reflexão deseja indicar algumas chaves de leitura para o Documento. Aparecida, a nosso ver, é uma tomada oficial de consciência de que a ação evangelizadora não pode mais repousar sobre o pressuposto de cristandade, colocando todos os esforços na manutenção do que se tem. Identidade e missão tornam-se palavras chaves, linhas de identificação dos aspectos específicos que, a partir das conclusões, forem gradualmente assumidos no futuro. 


\section{As Conferências Continentais e Aparecida}

\subsection{Finalidade pastoral}

Nesta leitura mais ampla, é preciso inicialmente considerar a finalidade das Conferências continentais. Trata-se, como bem sabemos, de uma realidade própria da América Latina e do Caribe, cujo objetivo é eminentemente pastoral. Estas Conferências buscam respostas para a concretização do mandato evangelizador no hoje do Continente. Os textos que têm refletido sobre a história das Conferências Episcopais latino-americanas ajudam muito a contextualizar e perceber qual a amplitude, mas também o limite histórico de cada Conferência. Esta observação é importante para que se evite projetar para dentro de Aparecida pesos que a Conferência não tinha condições de carregar. Algumas questões, por exemplo, dizem respeito à totalidade da Igreja, transcendendo, portanto, os limites do Continente. Mesmo no que diz respeito à abordagem destas questões universais, é preciso considerar a dimensão continental, coletiva ou comunitária da Conferência. Os problemas universais possuem visões distintas de acordo com a realidade sociocultural e eclesial das Igrejas Particulares representadas em Aparecida. Algo que para uma determinada Igreja particular é tranqüilo, para outras pode não ser e vice-versa.

\subsection{O hoje de Aparecida}

O primeiro passo na compreensão de Aparecida consiste em perguntar qual é este hoje que motivou a proposta e acompanhou a realização da Conferência. As Conclusões se referem a este hoje especialmente no segundo capítulo, intitulado Olhar dos discípulos missionários sobre a realidade [33 a 100]. Para esta leitura da realidade, o capítulo 2 segue a linha do Documento de Participação e da Síntese das Contribuições. Mais do que uma definição conceitual dos desafios, o capítulo apresenta situações que alegram e situações que preocupam.

É fato que o segundo capítulo usa bastante a palavra globalização ${ }^{1}$. Chama a atenção para o alcance universal de determinados processos e mu-

\footnotetext{
${ }^{1}$ AP 34 - "A novidade destas mudanças, diferentemente do ocorrido em outras épocas, é que elas têm um alcance global que, com diferenças e matizes, afetam o mundo inteiro. Habitualmente elas são caracterizadas como o fenômeno da globalização..." Convém acompanhar as reflexões que antecederam a Conferência e que aparecem no volume Evangelización de la cultura hoy. Oportunidades y Amenazas, Bogotá, Celam, 2007, de modo especial os capítulos da $3^{\mathrm{a}}$ parte.
} 
danças. Lembra que tais mudanças globais [34] afetam profundamente a vida dos povos [33], trazendo conseqüências para todos os campos da vida social e também, naturalmente, para a religião [35], de modo que, para Aparecida, o termo globalização não possui apenas sentido geográfico. É possível ver também a dimensão sociocultural e religiosa das mudanças. Na verdade, tudo muda em todos os lugares. Esta é a realidade nova que suscitou o desejo da Conferência.

Uma das indicações mais importantes para a compreensão destas mudanças globais aparece no $\mathrm{n}^{\mathrm{o}} 44$, tornando-se o mesmo significativa chave de compreensão para toda a realidade descrita. Trata-se do termo mudança de época. A expressão já tinha sido mencionada no Documento de Participação ${ }^{2}$. A Síntese das Contribuições apresenta a mesma expressão com os mesmos conteúdos ${ }^{3}$. As Conclusões mantiveram a indicação do termo no $\mathrm{n}^{\circ}$ 44, dentro do âmbito da cultura. Esta opção, longe, porém, de reduzir a importância deste eixo de compreensão, alarga-o e mesmo o ratifica. Isto porque, mais do que o próprio termo, o capítulo 2 menciona outras expressões que vão caracterizados esta mudança de época e sua incidência sobre a ação evangelizadora:

- 37 - Crise de sentidos, sentidos parciais sem a possibilidade de um sentido único.

- 38 - A preciosa tradição (cristã e católica) do Continente começa a se diluir.

- 39 - "Um dos fatos mais desconcertantes e originais que vivemos no presente: nossas tradições culturais já não se transmitem de uma geração à outra com a mesma fluidez que no passado.

Ao que tudo indica, aqui está o hoje de Aparecida. São mudanças tão estruturais que afetam não apenas a realidade circundante. Afetam - e aqui se encontra a novidade - os próprios critérios para compreender e julgar esta mesma realidade. Não se trata somente da transformação dos aspectos objetivos. Se assim fosse, poderíamos utilizar a expressão época de mudanças. Trata-se, na verdade, de alterações tão profundas, tão globalizadas, que afetam os critérios de compreender e julgar. Daí a utilização do termo mudança de época.

\footnotetext{
${ }^{2}$ DP 94 - "A passagem para o terceiro milênio é o símbolo de uma mudança de época cuja transição ainda perdura”. Outras referências à mesma expressão no Documento de Participação: $97,106,112$.

${ }^{3}$ SC 353 - “... estamos vivendo uma mudança de época que ilude a uns e desorienta a outros..."
} 


\subsection{A importância desta mudança}

Os três números acima indicados [37 a 39] apontam para sinais decisivos deste momento histórico caracterizado como mudança de época: crise de sentidos, ausência de sentido único e dificuldade para a transmissão das tradições às gerações seguintes. $\mathrm{O}$ que, até então, era tido como tranqüilo e unificador, nas culturas do continente tende a desaparecer, pondo em risco a própria transmissão da fé. Este fato, para ficarmos no âmbito das Conferências, é novo. É verdade que Puebla e Sto. Domingo já acenavam para ele ${ }^{4}$, mas é Aparecida quem o vai assumir com determinação. Por meio do termo mudança de época, com tudo que ele implica, podemos dizer que Aparecida destaca a importância também relação entre fé e cultura para a compreensão da realidade, sem, no entanto, deixar de lado as preocupações com a incidência da fé sobre a vida social, política e econômica ${ }^{5}$. Importa, nesta etapa da recepção, compreender como estas incidências se articulam com a crise de sentidos e mesmo com a ausência de um sentido único. A questão se coloca nos seguintes termos: como pensar nas implicações sociais do Evangelho se até mesmo a relação com o Evangelho e sua transmissão já não se fazem, no dizer de Aparecida, de modo tão tranqüilo?

Aparecida é, pois, um convite a assumirmos de modo inequívoco o fato de estarmos em tempo de pluralismo cultural e religioso, em que o cristianismo sai do centro da cena, deixando de ser o eixo articulador da totalidade da vida. Esta questão da ruptura entre evangelho e cultura se torna urgente e mesmo prioritária, na medida em que, durante séculos, a integração entre ambos tem representando um dos mais significativos eixos da ação evangelizadora. A novidade consiste no fato que os vínculos entre o Evangelho e a(s) cultura(s) do Continente tendem a fenecer cada vez mais. Esta ruptura é, para a América Latina, uma realidade nova. A principal conseqüência está no fato de que os mecanismos culturais que, durante séculos, garantiram a transmissão da fé já não são mais capazes de fazê-lo, pelo menos na intensi-

\footnotetext{
${ }^{4}$ Puebla 76-77: “Até o instante em que nosso continente foi alcançado e envolvido pela vertiginosa corrente de mudanças culturais, sociais, econômicas, políticas e técnicas da época moderna, o peso da tradição ajudava a comunicação do Evangelho: o que a Igreja ensinava do púlpito era ciosamente recebido no lar e na escola e sustentado pelo ambiente social. Hoje em dia já não acontece o mesmo. O que a Igreja propõe é aceito ou não, dentro de um clima de mais liberdade, com marcado sentido crítico...". Sto. Domingo 232 "observa-se na nossa realidade social o crescente desajuste ético-moral, em especial a deformação da consciência, a ética permissiva e uma sensível queda do sentido do pecado. Decresce o influxo da fé, perdese o valor religioso, desconhece-se a Deus como sumo bem e último juiz..."

${ }^{5}$ Basta ver as indicações do cap. $2^{\circ}$ sobre a leitura da realidade ou as opções de ação que aparecem nos caps. $8^{\circ}$ e seguintes.
} 
dade de antes. Embora o termo não seja mencionado em Aparecida, pode-se dizer que estamos em tempos de exculturação. Esta expressão tem sido utilizada para o catolicismo na Europa, onde a Igreja vem deixando de ser uma referência implícita ou um padrão de comportamento para a vida de pessoas e grupos ${ }^{6}$. Aparecida nos ensina a não restringir o olhar, no sentido de que a exculturação é realidade somente européia. Num mundo globalizado, o Oceano Atlântico não é barreira para a mudança de época.

Exculturação significa o enfraquecimento na relação entre o Evangelho e a(s) cultura(s) de tal modo que as referências ético-existenciais destas mesmas culturas já não são marcadas pelos os valores do Evangelho. Interessante observar que, já na abertura de Santo Domingo, o Papa João Paulo II acenava para esta ruptura através de duas indicações: a eliminação de valores religiosos fundamentais e a introdução de concepções inaceitáveis do ponto de vista cristão ${ }^{7}$. Em Aparecida, o Papa Bento XVI, após se referir à presença do Evangelho na vida dos povos latino-americanos durante mais de cinco séculos, afirma a mesma ruptura na medida em que declara estar "em jogo o desenvolvimento harmônico da sociedade e a identidade católica de seus povos ${ }^{8}$.

No atual momento da história ocidental da humanidade e, em nosso caso, na América Latina, a crescente separação entre os valores do Evangelho e as referências maiores das culturas se manifesta tanto nos fatos em si quanto nos critérios de enfrentamento. No caso dos fatos ou desafios, como pensar em uma sociedade ou cultura em rica articulação com o Evangelho quando a vida se encontra ameaçada nas mais diversas instâncias? No caso dos critérios, como pensar em compreender toda a realidade a partir de Jesus Cristo, quando tantas possibilidades culturais e religiosas se apresentam?

A relevância destas questões liga-se ao fato que, enquanto nos ambientes de maior vinculação entre evangelho e cultura, o lógico é ser cristão, ou seja, observar as indicações do sentido unificante, nos ambientes marcados pelo pluralismo, o Evangelho perde a lógica sociocultural. Perde sua plausibilidade. Surgem, então, os graves problemas da transmissão da fé às novas gerações [100d e 365] e da manutenção dos que se assumem como cristãos.

\footnotetext{
${ }^{6}$ cf.: DANIÉLE HEVIEU-LÉGER, Lê pèlerin et le converti. La religion en mouvement, Paris: Flammarion, 1999. De modo especial, o $1^{\circ}$ cap., pp. 29-60. Da mesma autora: Catholicisme, la fin d'um monde, Paris: Bayard, 2003, pp. 275ss.

7 Cf. JOÃO PAULO II, Discurso inaugural à IV Conferência Geral do Episcopado Latinoamericano, Sto. Domingo, 12 de outubro de 1922, n. 21

8 Cf. BENTO XVI, Discurso inaugural à V Conferência Geral do Episcopado Latinoamericano, Aparecida, 13 de maio de 2007, $\mathrm{n}^{\mathrm{o}} 1$.
} 
Surge, concomitantemente, o problema da incidência ético-existencial do cristianismo que, na sua identidade, é sal, fermento e luz.

Problemas específicos e igualmente graves, como, por exemplo, a exclusão social ou as ameaças à vida, precisarão ser enfrentados com clareza de critérios e firmeza de identidade. Os fatos, ou seja, os desafios e as urgências são claros. O problema está nos critérios que identificam posturas e apontam soluções. Voltar-se, pois, aos fundamentos últimos não significa abandonar as causas relevantes, que tanto marcaram o rosto da Igreja do Continente. Ao contrário, se não nos voltarmos com atenção para as implicações que uma mudança de época apresenta para o anúncio do Evangelho, estaremos correndo o risco de, a médio prazo, nos atrapalharmos nos critérios para o enfrentamento das graves questões que dizem respeito aos cristãos e a todos em geral.

\section{Jesus Cristo e o critério para recomeçar}

Vivemos num tempo de pluralismo, em que circulam inúmeras formas de compreender a realidade, tanto em nível sociocultural quanto em nível pessoal. Vários são os caminhos. Neste contexto, o ser humano se torna fragmentado nos critérios de enfrentamento da realidade. Diante deste quadro, Aparecida indica como pista evangelizadora central o recomeçar a partir de Cristo [41]. Trata-se do esforço por reunir o conjunto de todos os significados da realidade em uma "compreensão unitária, que permita exercer a liberdade com discernimento e responsabilidade" [42, grifo nosso].

Importa destacar que não se trata apenas da questão, por si importante, de teologicamente se afirmar a centralidade de Jesus Cristo. Estamos também diante de uma questão antropológica relevante, a saber, a importância de um eixo articulador para o conjunto da vida, em face de uma realidade fragmentada. Na essência do Evangelho, encontra-se não apenas a centralidade de Jesus Cristo como também o caráter antropologicamente indispensável de um eixo articulador para a totalidade da vida de pessoas, grupos e povos. Jesus não se propõe apenas a este o àquele setor da vida. Sua proposta é abrangente, totalizante, de tal modo que não haja uma única instância onde os valores do Evangelho não penetrem. É neste sentido que se pode compreender a referência bíblica para o tema da V Conferência: "Eu sou o Caminho, a Verdade e a Vida!" (Jo 14,6).

A questão de se recomeçar a partir de Jesus Cristo apresenta, no entanto, uma inevitável preliminar: de que Jesus Cristo estamos falando? Ao que tudo indica, um significativo eixo cristológico em Aparecida se manifesta na referência a 2 Cor 8,9 , texto mencionado pelo Papa Bento XVI, em seu Dis- 
curso Inaugural ${ }^{9}$ e repetido no Documento de Aparecida [31 e 392]. A repetição é pequena: somente duas vezes. É, no entanto, decisiva. Ao fundamentar a opção preferencial pelos pobres, a referida frase atinge e fundamenta a proposta missionária presente em Aparecida, manifestando, deste modo, uma tendência cristológica da V Conferência. Trata-se da cristologia da saída de si, do esvaziamento, da gratuidade, do encontro, da alteridade e da missão. É esta concepção de Jesus Cristo que leva a Igreja a ser cada vez mais missionária e samaritana [27].

Este fato é importante porque mudanças de épocas não significam vazio nos conteúdos. O atual período traz em si uma concepção usual de Jesus Cristo, com a qual é preciso dialogar. Na medida em que o religioso sai do centro da cena e o econômico tende a ocupar o lugar central, também o fenômeno religioso se vê afetado [35] e a relação com o transcendente passa a ser economicizada. Torna-se predominantemente relação de causa-e-efeito, troca, escambo. O Jesus Cristo que emerge neste contexto é muito mais o Jesus Cristo taumaturgo, produtor de milagres, prodígios, curas e afins. À primeira vista, é possível supor que a ruptura entre evangelho e cultura(s), no Continente, não esteja acontecendo, uma vez que o nome de Jesus Cristo continua sendo pronunciado e até mesmo invocado com maior freqüência. No entanto, para o Evangelho, será sempre necessário se indagar se, ao uso do nome de Jesus Cristo, corresponde, efetivamente, uma postura de vida coerente com o mesmo Jesus. Não soa estranho constatar que, concomitantemente a tanta invocação do nome de Jesus aconteçam tantas ameaças à vida, tantos desrespeitos ao bem comum, tamanha insensibilidade ao sofrimento dos mais pobres? Nunca será demasiado repetir que, entre o Jesus taumaturgo e o Jesus da Kénosis, acontecem relações distintas. No caso do Jesus taumaturgo, a relação se dá muito mais com aquilo que o taumaturgo pode fornecer. São relações funcionais e de interesse. No caso do Jesus da Kénosis, a relação se dá com a pessoa, independentemente daquilo que ela possa oferecer.

Convém olhar com atenção para dois números no Documento de Aparecida. Eles ajudam no esclarecimento da opção cristológica da Conferência. São os números 131 e 357. Os grifos são nossos:

131 - O chamado que Jesus, o Mestre, faz, implica numa grande novidade. Na antiguidade, os mestres convidavam seus discipulos a se vincular com algo transcendente e os mestres da Lei propunham a adesão à Lei de Moisés. Jesus convida a nos encontrar com Ele e a que nos

${ }^{9}$ DI 3 
vinculemos estreitamente a Ele porque é a fonte da vida e só Ele tem palavra de vida eterna. Na convivência cotidiana com Jesus e na confrontação com os seguidores de outros mestres, os discípulos logo descobrem duas coisas originais no relacionamento com Jesus. Por um lado, não foram eles que escolheram seu mestre foi Cristo quem os escolheu. E por outro lado, eles não foram convocados para algo (purificar-se, aprender a Lei...), mas para Alguém, escolhidos para se vincular intimamente a sua pessoa... viver seu destino e assumir sua missão de fazer novas todas as coisas.

357. Mas o consumismo hedonista e individualista, que coloca a vida humana em função de um prazer imediato e sem limites, obscurece o sentido da vida e a degrada. A vitalidade que Cristo oferece nos convida a ampliar nossos horizontes e a reconhecer que abraçando a cruz cada dia entramos nas dimensões mais profundas da existência. O Senhor que nos convida a valorizar as coisas e a progredir, também nos previne sobre a obsessão por acumular: Não amontoem tesouros nesta terra (Mt 6,19). "De que serve ao homem ganhar o mundo, mas perder a sua vida?" (Mt 16,26). Jesus Cristo nos oferece muito, inclusive muito mais do que esperamos. À Samaritana, ele dá mais do que a água do poço. À multidão faminta ele oferece mais do que o alívio da fome. Entrega-se a si mesmo como a vida em abundância. A vida nova em Cristo é participação na vida de amor do Deus Uno e Trino. Começa no batismo e chega a sua plenitude na ressurreição final.

Cientes de que, nestes tempos em que a complexidade da vida, a exclusão social e a aguda centralização sobre o próprio eu contribuem para que o fenômeno Jesus Cristo taumaturgo não seja exclusividade desta ou daquela confissão religiosa, mas desafio transconfessional, deparamo-nos, em termos de ação evangelizadora, com um sério desafio cristológico. Os próximos anos pedem de nós um forte empenho na afirmação da cristologia da kénosis até a cruz (Filip 2,5ss; 1 Cor 1,18-25). O Jesus Cristo que pregamos deve estar, pois, em consonância com o que foi afirmado em Aparecida. Mesmo com a melhor das intenções, a ação evangelizadora precisa estar atenta para não oferecer Jesus Cristo subordinado a uma concepção de Deus bem mais adequada ao Antigo Testamento. Quem oferece algo como objetivo maior ou último, seja lá o que for, mesmo que não seja a Lei no sentido estrito do termo, encontra-se ainda no horizonte veterotestamentário. Esquece-se de que, no mistério de Jesus Cristo, existe uma irrenunciável dimensão imanipulável, que ultrapassa as relações fechadas e imediatistas, baseadas na predominância de milagres, curas e prodígios, válidos por si mesmo, como finalidade última. Eis porque precisamos olhar com bastante atenção para uma certa 
cristologia da prosperidade, tão característica destes tempos em que praticamente tudo é aferido a partir da eficácia imediata. Convém avaliar bastante se esta chamada cristologia da prosperidade não acaba sendo geradora, a médio prazo, de frustrações e ateísmo: o que resta quando se verifica que as eficácias garantidas em nome de Jesus Cristo não ocorrem?

\section{Conversão pastoral}

Como, pois, apresentar, nesta mudança de época, uma cristologia da kénosis, da gratuidade, da samaritana saída de si em busca da ovelha perdida? A resposta de Aparecida é muito dura. Ela aparece no título do item 7.2, imediatamente antes do número marginal 365. Aparecida aponta o problema e indica a solução, convocando a uma conversão pastoral.

O problema é mencionado, por exemplo, quando se analisa a realidade da paróquia: o número de católicos nas celebrações é limitado [173], enquanto o número dos distanciados e mesmo daqueles que não conhecem a Cristo é imenso ${ }^{10}$. O importante é perceber que não se trata de perda numérica ao estilo de freguesia que se desloca para o concorrente. Trata-se de responsabilidade missionária, compromisso com a transmissão da fé e sua incidência sobre pessoas, grupos e sociedade. Nos regimes de forte identificação entre evangelho e cultura, regimes que costumamos chamar de cristandade, pressupõe-se que a iniciação cristã seja feita em concomitância com a iniciação sociocultural. Trata-se do chamado catecumenato social, atitude surgida na Igreja a partir do séc. V, quando a sociedade, então considerada cristã, passou a realizar as funções de iniciação cristã. Na medida em que Aparecida assume oficialmente a quebra desta forte identificação também em termos de América Latina e Caribe, a conseqüência imediata é a mudança no estilo de se fazer pastoral.

Esta é a razão pela qual Aparecida é tão severa quando fala de um tipo de ação pastoral obsoleta. Dois são os números centrais neste ponto. Também aqui os grifos são nossos:

370. A conversão pastoral de nossas comunidades exige que se vá além de uma pastoral de mera conservação para uma pastoral decididamente missionária. ...

\footnotetext{
${ }^{10}$ Este assunto foi estudado, por exemplo, na obra que refletiu sobre a mobilidade religiosa no Brasil: FERNANDES, Silvia Regina Alves (Org.) . Mudança de religião no Brasil - desvendando sentidos e motivações. 1. Ed. São Paulo: Palavra e Prece, 2006. v. 01. 235 p.
} 
365. Esta firme decisão missionária deve impregnar todas as estruturas eclesiais e todos os planos pastorais de dioceses, paróquias, comunidades religiosas, movimentos e de qualquer instituição da Igreja. Nenhuma comunidade deve se isentar de entrar decididamente, com todas suas forças, nos processos constantes de renovação missionária e de abandonar as ultrapassadas estruturas que já não favoreçam a transmissão da fé.

Pode-se ainda acrescentar o $n^{\circ} 366$, uma convocação geral à conversão pastoral:

366. A conversão pessoal desperta a capacidade de submeter tudo a serviço da instauração do reino da vida. Os bispos, presbíteros, diáconos permanentes, consagrados e consagradas, leigos e leigas, são chamados a assumir uma atitude de permanente conversão pastoral, que envolve escutar com atenção e discernir "o que o Espírito está dizendo às Igrejas" (Ap $2,29)$ através dos sinais dos tempos nos quais Deus se manifesta.

Para concretizar a conversão pastoral, Aparecida apresenta várias indicações. Quatro se destacam, nesta abordagem introdutória: a iniciação cristã, a setorização, a ministerialidade e o compromisso pela vida.

\subsection{Iniciação cristã}

Aparecida indica a urgência de se buscarem caminhos de explícita iniciação à fé, não se repousando mais sobre a idéia de que, iniciadas nos mecanismos de uma sociedade cristã, as pessoas tenderiam a se tornar também cristãs. É neste sentido que se entende a força de expressões como as ultrapassadas estruturas que já não favoreçam a transmissão da fé [365]. Trata-se de posturas pastorais que, repousando sobre a manutenção ou conservação do que já existe [370], acabam por, na prática, desconhecer o fato de que os atuais mecanismos para a iniciação sociocultural não conduzem ao Jesus Cristo da Kénosis. Parecem tender muito mais para o Jesus Cristo taumaturgo.

Iniciação Cristã, como bem sabemos, liga-se diretamente à transmissão da fé e ao ingresso na comunidade dos discípulos. Trata-se de realidade inerente ao cristianismo, variando, porém, nas formas de concretização histórica, entre as quais se insere o já referido catecumenato social. Neste, a ação pastoral explícita se concebe muito mais como momento segundo, a completar doutrinária e intelectualmente a experiência 
feita em família e em sociedade. Na medida, porém, que se assume a crescente exculturação, desaparece, por conseqüência, a base sobre a qual se constrói o catecumenato social e cresce a importância e mesmo a urgência de uma iniciação cristã explícita, urgente e prioritária [294 e 297].

Para Aparecida, a iniciação cristã explicitada pastoralmente faz parte de um processo mais amplo, no qual a catequese deixa de ser sazonal, isto é, como preparação para sacramentos em determinados momentos da vida, para se tornar permanente [298]. Deixa também de ser meramente doutrinal, preocupando-se, então, com o cultivo da "amizade com Cristo na oração, o apreço pela celebração litúrgica, a experiência comunitária, o compromisso apostólico mediante permanente serviço aos demais" [299].

Aparecida propõe a superação os atuais cursos de preparação aos sacramentos da iniciação cristã. Ao assumir uma "clara e decidida opção pela formação dos membros de nossas comunidades" [276], incorporando nesta categoria tanto os não batizados quanto os batizados, mas não suficientemente evangelizados [288], ajuda a superar a tentação de apenas adaptar os atuais cursos preparatórios a sacramentos. A questão abordada por Aparecida não se restringe à melhoria dos recursos pedagógicos e ao uso de técnicas atualizadas de dinâmica de grupo. O que efetivamente deve mudar é o pressuposto. O que, em épocas anteriores era fornecido socioculturalmente, precisa, na atualidade, se explicitado pela ação evangelizadora: o "encontro pessoal, cada vez maior, com Jesus Cristo, perfeito Deus e perfeito homem, experimentado como plenitude da humanidade"[289]. Trazendo a questão mistagógica para o centro da reflexão, Aparecida chama a atenção para itinerários evangelizadores diferenciados, respeitosos dos processos individuais, comunitários e sociais [279, 281 e 290].

Neste breve conjunto de reflexões de Aparecida sobre a iniciação cristã, convém por fim deter nossa atenção em uma afirmação que, embora breve, como tantas outras no conjunto das Conclusões, nem por isso deixa de ser importante e convidativa a posterior aprofundamento. Trata-se da observação a respeito das razões pelas quais pessoas deixam a Igreja Católica, sob a alegação de terem realizado, exatamente nestes grupos, o encontro com Jesus Cristo. Aparecida não acredita tanto em motivos de ordem doutrinal para este êxodo. Opta por aspectos de natureza mais vivencial [225], ligados, por certo, à formação bíblico-doutrinal, mas também à experiência religiosa, à vivência comunitária e ao compromisso comunitário [226]. Ordem doutrinal liga-se mais à dimensão racional de uma catequese posterior à iniciação cristã. Vivencial pode ser boa tradução para a experiência inicial de fascínio por Jesus e decorrente acolhimento. Eis porque Aparecida exige que, ao lado 
da recentralização da iniciação cristã, ocorra também a reconfiguração das formas comunitárias de se viver a fé.

\subsection{Setorização}

A questão da iniciação cristã remete necessariamente à questão da experiência comunitária Neste processo de formação doutrinal e identidade explicitamente católica [297], Aparecida chama a atenção para a dimensão comunitária da experiência cristã. É bem possível que, numa primeira leitura de Aparecida, a atenção se volte mais para a relação entre discipulado e missão. Esta foi a referência maior de toda a Conferência. Basta considerar o lema. Assim transparece também nas Conclusões, quando, em todo o $4^{\circ} \mathrm{ca}-$ pítulo, a articulação central é exatamente entre discipulado e missionariedade, como "duas faces da mesma moeda" [146], expressão utilizada pelo Papa Bento XVI no Discurso Inaugural ${ }^{11}$. Todavia, logo após afirmar o vínculo entre discipulado e missão, Aparecida, no $5^{\circ}$ capítulo, se volta para a comunhão. Dois textos são esclarecedores:

156. A vocação ao discipulado missionário é con-vocação à comunhão em sua Igreja. Não há discipulado sem comunhão. Diante da tentação, muito presente na cultura atual de ser cristãos sem Igreja e das novas buscas espirituais individualistas, afirmamos que a fé em Jesus Cristo nos chegou através da comunidade eclesial e ela "nos dá uma família, a família universal de Deus na Igreja Católica. A fé nos liberta do isolamento do eu, porque nos conduz à comunhão" Isto significa que uma dimensão constitutiva do acontecimento cristão é o fato de pertencer a uma comunidade concreta...

278d "não pode existir vida cristã fora da comunidade: nas famílias, nas paróquias, nas comunidades de vida consagrada, nas comunidades de base, nas outras pequenas comunidades e movimentos" (Grifo nosso)

Também neste aspecto, a questão não é de natureza teológica. É pastoral. Não se discute o caráter essencial da dimensão comunitária da fé cristã. O que se discute é o modo como esta dimensão comunitária se vai concretizar, ou seja, o modo como as comunidades eclesiais se vão configurar em nossos dias. O tema da (re)configuração comunitária liga-se diretamente com o anterior, o da iniciação cristã, pois é da essência do cristianismo que o

${ }^{11}$ DI 3 
acesso à pessoa e à mensagem de Jesus seja mediado pela comunidade dos discípulos..

Os textos mais relevantes aparecem em dois grandes blocos: números 178 e seguintes e 307 e seguintes. A indicação é clara: pequenas comunidades, tanto as comunidades eclesiais de base, quanto outras formas de comunidade [307 e 180]. Estas pequenas comunidades, sejam CEBs ou outras formas, encontram sua identidade e seu valor nas características que aparecem, por exemplo, nos números 178 e 179:

- Relações de amizade, confiança e respeito mútuo.

- Conhecimento maior da Palavra de Deus.

- Educação dos adultos na Fé

- Surgimento e amadurecimento dos diversos ministérios e serviços leigos.

- Compromisso social em nome do Evangelho.

- Comunhão com a Igreja e compromisso com o projeto diocesano de pastoral.

A setorização ou capilarização se torna importante porque, para a maioria de nossa gente, a relação com a Igreja se concretiza na paróquia territorial. O problema consiste no fato que, pelo número de fiéis que devem atender, pelo estilo pastoral com que às vezes são conduzidas, muitas paróquias não são capazes de satisfazer aos anseios por caminhos mais comunitários de viver a fé. Este anseio se dirige, então, para novas formas associativas, indicando a necessidade de novas estruturas comunitárias, além das conhecidas paróquias territoriais.

Torna-se, portanto, urgente a reconfiguração destas paróquias em comunidades de comunidades ${ }^{12}$. Não se nega que as paróquias têm prestado relevante serviço evangelizador, sendo consideradas "células vivas da Igreja e lugar privilegiado no qual a maioria dos fiéis tem uma experiência concreta de Cristo e a comunhão eclesial" [170]. Torna-se, porém, necessário reconhecer que, diante das grandes mudanças ocorridas nas últimas décadas, as paróquias necessitam passar pela "reformulação de suas estruturas, para que sejam redes de comunidades e grupos, capazes de se articular, conseguindo que seus membros se sintam realmente discípulos e missionários de Jesus Cristo em comunhão" [172-173].

Aparecida valoriza bastante as diversas formas associativas e comunitárias, nas quais seja possível experimentar a gratuidade dos relacionamentos e o compromisso missionário. Nesta valorização, recorda o contributo das Comunidades Eclesiais de Base, no sentido que elas "permitiram ao povo chegar a um conhecimento maior da Palavra de Deus, ao compromisso soci-

${ }^{12}$ Conforme já indicava Sto. Domingo 58 e 60. 
al em nome do Evangelho, ao surgimento de novos serviços leigos e à educação da fé dos adultos". Chama também a atenção para "outras formas válidas de pequenas comunidades, e inclusive redes de comunidades, de movimentos, grupos de vida, de oração e de reflexão da palavra de Deus"[178, 180 e 307].

Em síntese, podemos afirmar que a conversão pastoral solicitada por Aparecida aponta para "a setorização (das paróquias) em unidades territoriais menores, com equipes próprias de animação e de coordenação que permitam maior proximidade com pessoas e grupos que vivem na região" [372]. O caminhar histórico das paróquias, com tantas conquistas e sucessos, com experiências pastorais bem sucedidas em outras épocas, aumenta o receio de passar de uma paróquia centralizada num único prédio, onde acontecem praticamente todas as atividades, para a paróquia como comunidade de comunidades espalhadas por todo o território. Maior receio acontece quando a rede de comunidades se liberta até mesmo do território, gerando comunidades ambientais [517f], nas quais se inserem as conhecidas comunidades de aliança ou de vida, em geral, ligadas a movimentos e também os setores específicos de vida. Esta mudança é grande. Contudo, é também urgente e mesmo irreversível [365].

\subsection{Ministerialidade}

Também neste ponto, o dos ministérios, esta Semana Teológica apresenta uma comunicação específica. Nesta reflexão introdutória, cabe a observação de que o tema ministérios assume caráter de centralidade na proposta evangelizadora de Aparecida. Assim como não há experiência de Jesus Cristo, ou seja, discipulado missionário, sem iniciação cristã e sem efetiva vida de comunidade, tampouco estas ocorrerão se não houver simultânea acentuação da dimensão ministerial.

Aparecida indica esta importância. Suas indicações não são listas exaustivas. Valem como exemplos da ampla gama de ministérios que podem ser criados, em vista à missão. O número $99 \mathrm{c}$ se refere a ministérios mais diretamente ligados à vida das comunidades. Pode-se mesmo dizer que se trata dos que levam adiante, junto com o ministério ordenado, a setorização. São delegados da Palavra, animadores de assembléias e de pequenas comunidades, de movimentos eclesiais e um grande número de pastorais específicas.

Pensemos, por exemplo, na relação entre iniciação cristã e ministérios. O Ritual da Iniciação Cristã de Adultos, publicado no início da década de 70, 
já mencionava inúmeros ministérios ${ }^{13}$, manifestando claramente o caráter indispensável de uma rede de ministérios variados e específicos. Aparecida segue na mesma linha de pensamento.

É por isso que, alargando o horizonte de compreensão ministerial em Aparecida, podemos perceber que, para cada opção pastoral, decorre a exigência de novos ministérios, no âmbito, por exemplo, do ecumenismo [231] ou do mundo da educação [483]. Destacam-se ainda ministérios da escuta e aconselhamento [397]. O importante é ter clareza de que, assim como não basta setorizar as grandes paróquias sem a correspondente atuação dos diversos ministérios de cunho mais missionário, também não basta estimular o surgimento destes ministérios se não se assume a conversão pastoral que Aparecida nos solicita.

\subsection{O compromisso pela vida}

Por fim, Aparecida indica o que poderíamos chamar de perfil espiritual para a Igreja do Continente nos próximos anos. O discipulado e a missionariedade de nossos dias apresentam uma irrenunciável exigência: a defesa e a promoção da vida nas diversas instâncias. No sentido mais amplo do termo, a vida se torna valor central para a concretização da fé em todas as situações cotidianas. O discípulo-missionário é chamado a assumir que a vivência de sua fé não se mede, por exemplo, pelo consumismo de prodígios e eficácias imediatas, mas sim pelo compromisso com a vida. Mais do que embates religiosos, com quem nada mais deseja que arrebanhar fiéis, o discípulo missionário sabe que seu caminho é o do testemunho de amor e luta pela vida $[159,233]$. O interessante é perceber que este mesmo compromisso com a vida, tão pertinente à identidade cristã, é também relevante para a incidência evangelizadora em nossos dias. A questão da vida é universal em vários sentidos. Atinge não apenas a abrangência dos problemas, que chegam ao nível planetário [66, 87], mas também a sensibilidade de todas as consciências preocupadas com um mundo mais humano [233].

Pela categoria de vida, se compreende o sentido da opção preferencial pelos pobres [391ss]. Uma das peculiaridades da fisionomia da Igreja latinoamericana e caribenha, esta opção se encontra na raiz de nossa fé [392], exigindo dos discípulos-missionários firme sensibilidade para todas as formas de dor, sofrimento e ameaça à vida. Aparecida mantém a mesma referência espiritual indicada por Puebla e Santo Domingo ${ }^{14}$ no sentido de ver nos ros-

\footnotetext{
${ }^{13}$ RICA, 41ss.

${ }^{14}$ Puebla 31 e Sto. Domingo 178.
} 
tos sofredores o rosto do próprio Cristo [392]. Através de uma longa lista de novas formas de sofrimento, Aparecida alarga a concepção de sofredor. Para Aparecida, onde a vida estiver fragilizada, ameaçada [396], a Igreja latinoamericana é chamada a ser sacramento de amor, solidariedade e justiça entre os povos. Temos, assim, o convite para assumirmos sempre mais este rosto comunitário, missionário, ministerial e solidário para as Igrejas do Continente.

\section{Résumé}

La 5 ème Assemblée des évêques de Amérique Latine et Caribe est arrivée à la conclusion que l'action pastorale doit s'adapter de manière rapide aux nouvelles exigences de vision et de compréhension pastorale, particulièrement en transformant le concept de paroisse e de territoire paroissial en communauté de communautés, ou réseau de communautés a fin d'atteindre in manière plus réelle a nouvelle réalité ecclésiale actuel.

Joel Portella Amado

Doutor em Teologia pela PUC-Rio Coordenador Diocesano da Pastoral e Professor do Departamento de Teologia da PUC-Rio 